\title{
A Preliminary Design of Flight Test Conditions for a Sub-scale RBCC Engine using a Sounding Rocket
}

\author{
Hye-Sung Kim*, Kui-Soon Kim**, Se-Jong $\mathrm{Oh}^{* *}$ and Jeong-Yeol Choi ${ }^{* * *}$ \\ Pusan National University, Busan 46241, Republic of Korea
}

Won-Seok Yang****

Agency for Defense Development, Chungnam, Haemi 32024, Republic of Korea

\begin{abstract}
Various R\&D programs for rocket-based combined cycle (RBCC) engines have progressed worldwide for the space development and the defense applications. As a way toward indigenous domestic RBCC program, a preliminary design of flight test conditions was studied in this study for a sub-scale RBCC engine using a sounding rocket. Launch and flight profiles were calculated for several booster options and compared with that of HyShot II program. The result shows that the Korea Sounding Rocket-II (KSR-II) is a proper candidate to perform the flight test available in Korea. The recommend flight test conditions with KSR-II are Mach 6.0 with a test vehicle of $230 \mathrm{~kg}$ and Mach 7.4 with $50 \mathrm{~kg}$. Present study will soon be followed by a design of sub-scale RBCC for a flight test using a sounding rocket.
\end{abstract}

Key words: Rocket-Based Combined Cycle (RBCC), flight test, sounding rocket, KSR-II.

\section{Introduction}

Various $R \& D$ programs for hypersonic flight vehicles have shown progress due to increasing needs worldwide for hypersonic aircrafts (e.g., the SR-72) and reusable launch vehicles. Many different types of hypersonic propulsion systems have been suggested since the benefits of scramjet propulsion were proven by Ferri, who first demonstrated supersonic combustion. Typical hypersonic propulsion systems include the dual mode ramjet/scramjet (DMR), dual combustion ramjet/scramjet (DCR), turbine-based combined cycle (TBCC), and rocket-based combined cycle (RBCC). The DMR has a mode transition between ramjet and scramjet mode, DCR uses subsonic combustion of the ramjet as a pre-burner, TBCC combines a ramjet/scramjet engine with a turbine system, and RBCC combines a ramjet/scramjet engine with a rocket system. Among these, RBCC is gaining attention due to its simpler design of a single flow path in comparison to the TBCC's multiple flow paths.

Flight test programs for hypersonic propulsion systems started from Kholod conducted by Russia and the Hyper-X program conducted by the USA in the 1990s. Australia first confirmed the supersonic combustion phenomenon in a flight environment through the HyShot II in 2002. The USA was the first to fly a hydrocarbon-fueled hypersonic vehicle through HyFly's Free-flight Atmosphere Scramjet Test Technique (FASTT) in 2005. Hypersonic flight test programs using a sounding rocket are expanding in order to acquire related technologies such as the HIFiRE (Hypersonic International Flight Research and Experimentation) program in the USA, in collaboration with Australia, and the LEA (Liotnii Experimental Apparat) program in France. Then, space powers including France, China, and India have conducted relevant flight tests. The details of the aforementioned flight test programs are introduced in Ref. [1].

In Korea, basic RBCC research is being performed at
This is an Open Access article distributed under the terms of the Creative Commons Attribution Non-Commercial License (http://creativecommons.org/licenses/by$\mathrm{nc} / 3.0 /$ ) which permits unrestricted non-commercial use, distribution, and reproduction in any medium, provided the original work is properly cited. (c) * Graduate student

** Professor, department of aerospace engineering

*** Professor, department of aerospace engineering, Corresponding author: aerochoi@pusan.ac.kr.

**** Researcher, the 7th R\&D institute -4 th Directorate 
the Korea Aerospace Research Institute (KARI), and it is expected that RBCC flight tests will play an important role in the development of related technologies. Accordingly, the Rocket Propulsion Laboratory at Pusan National University conducted a conceptual design of a RBCC engine for a flight test. This RBCC engine operates at Mach 6.0 at an altitude of $25 \mathrm{~km}$, and consists of a hypersonic intake, isolator, combustor, and nozzle, as shown in Fig. 1. Some typical designs are shown in Fig. 2. The designed RBCC showed that the specific impulses of upper and lower figure are about 3000 seconds on inviscid condition. These parametric studies showed that a high intake exit Mach number $M_{1}$ increases thrust and specific impulse, and a high combustor inlet pressure $P_{2}$ increases specific impulse but decreases thrust in the range considered in the preceding study [2].

In the present study, our goal is to choose a launch vehicle to load a sub-scale RBCC engine and design the flight test mission based on the preceding study. To achieve this, the paper developed a flight performance analysis program for a sounding rocket conducting the flight test. Then, the analysis program was verified by using overseas flight test cases. A domestic launch vehicle was selected as the sounding rocket that can reach Mach 6.0 at an altitude of around 25 $\mathrm{km}$. Finally, parametric studies were conducted in order to determine variations in payload and launch angle, and the paper determined a range of payloads and test Mach numbers that can be applied to the flight test.

\section{Methods of Analysis}

\subsection{Launch Vehicle Modeling}

The analysis model considers a slender two-stage launch

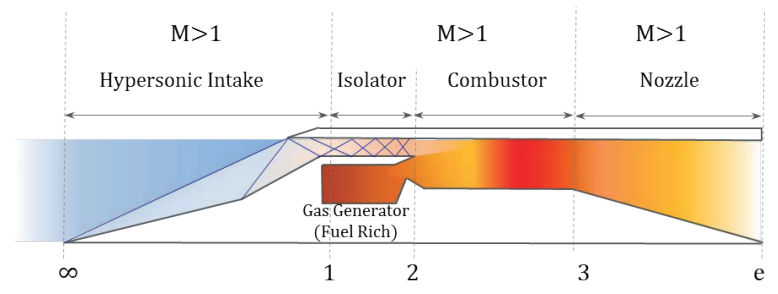

Fig. 1. Schematic of rocket-based combined cycle [2]

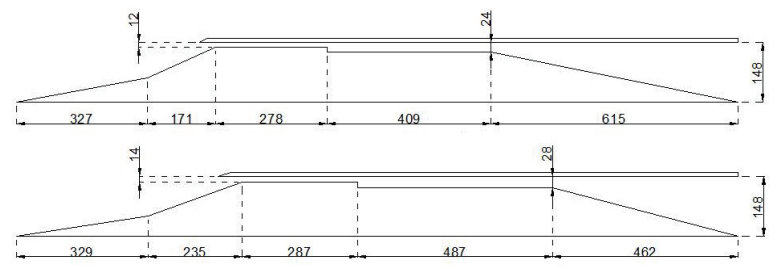

Fig. 2. Conceptual design of RBCC propulsion system [2] vehicle without wings, so the calculations include drag force but not lift force. The launch vehicle is assumed to be a twodimensional (2-D) point mass, and a trajectory of the vehicle was calculated. The governing equations are the differential equations of velocity and flight path angle shown in Eqs. (1) and (2). A fourth-order Runge-Kutta numerical method is applied to minimalize numerical errors [3].

$$
\begin{aligned}
& \frac{d v}{d t}=\frac{F}{m} \cos (\psi-\theta)-\frac{C_{D}}{m} \frac{\rho v^{2}}{2} \frac{\pi D^{2}}{4}-g \sin \theta \\
& \frac{d \theta}{d t}=\frac{1}{v} \frac{F}{m} \sin (\psi-\theta)-\frac{1}{v} g \cos \theta
\end{aligned}
$$

For ease of calculation, it is assumed that the thrust and mass flow rate of each stage are constant, and that stage separation occurs when the combustion on a former stage is finished completely. The analysis does not consider the kick-turn to reach a sub-orbital trajectory, but does consider a gravity-turn only in the range of dynamic pressure higher than $0.1 \mathrm{kPa}$, because the drag force due to the high angle of attack cannot be neglected.

A coasting flight section exists between the first and second stage powered flight to decrease drag, since excessively high speeds in the atmosphere creates unnecessary drag force. Through an iteration process of coasting time, the best results are derived for maximum Mach number in the descent section. The analysis program is composed of three modes: default mode, payload mode, and launch angle mode. For the default mode, the calculations were conducted along the coasting time step. For the payload mode and the launch angle mode, the parametric studies are related to the payload and launch angle, as the each variable. A flow chart of the analysis program is shown in Fig. 4.

\subsection{Aerodynamic Properties}

The proposed analysis program assumes that the properties of air are those specified by the International Standard Atmosphere (ISA), published by the International Civil Aviation Organization (ICAO). The properties are pressure, temperature, and density as a function of altitude.

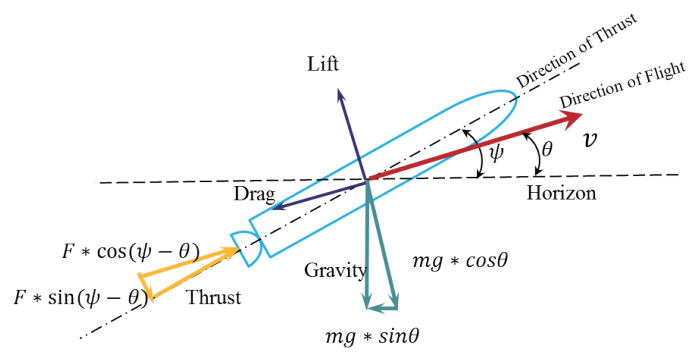

Fig. 3. Model of launch vehicle [3] 
The drag force is derived from a drag coefficient depending on the Mach number and launch vehicle shape including the diameter and length of the entire launch vehicle, and the length of the nose cone. It is noted that the drag coefficient is different depending on the flight environment (e.g., subsonic or supersonic speed, and coasting or powered flight). Equ. (3) shows drag caused by friction, Eqs. (4)-(6) represent the wave and pressure drag at subsonic speed, and Eqs. (7)-(9) are the wave and pressure drag at supersonic speed. The equations for the drag coefficient are below.

Friction drag (regardless of Mach number) :

$$
\left(C_{D 0}\right)_{\text {Friction }}=0.053\left(\frac{l}{d}\right)\left(\frac{M}{q l}\right)^{0.2}
$$

Wave and pressure drag (at subsonic speed) :

$$
\begin{aligned}
& \left(C_{D 0}\right)_{\text {Wave }}=0 \\
& \left(C_{D 0}\right)_{\text {Base,Coast }}=0.12+0.13 M^{2} \\
& \left(C_{D 0}\right)_{\text {Base }, \text { Power }}=\left(1-\frac{A_{e}}{S_{\text {ref }}}\right)\left(0.12+0.13 M^{2}\right)
\end{aligned}
$$

Wave and pressure drag (at supersonic speed) :

$$
\begin{aligned}
& \left(C_{D 0}\right)_{\text {Wave }}=\frac{3.6}{\left(\frac{l_{N}}{d}(M-1)+2\right)}, \\
& \left(C_{D 0}\right)_{\text {Base,Coast }}=\frac{0.25}{M} \\
& \left(C_{D 0}\right)_{\text {Base,Power }}=\left(1-\frac{A_{e}}{S_{\text {ref }}}\right)\left(\frac{0.25}{M}\right)
\end{aligned}
$$

\subsection{Program Verification}

The analysis program was verified by using overseas flight test cases in order to confirm the reliability of the calculated results. The calculated results were then compared to the flight test's mission profiles for HyShot II and HIFiRE VII, based on Refs. [5]-[6]. Specifications of the sounding rockets used in the verification process are shown in Table 1. The phased errors between the calculated results and the mission profiles of each flight phase are shown in Table 2-3.

The HyShot II flight test program showed the world's first supersonic combustion in a flight environment through an international consortium, led by the University of Queensland (UQ), Australia. The flight test used a $110 \mathrm{~kg}$ test vehicle, and Terrier-Orion Improved was used as the booster. The test conditions were Mach 7.6 to 7.4 at $35 \mathrm{~km}$ to $23 \mathrm{~km}$ altitude with a coasting time of $5.6 \mathrm{~s}$, and a launch angle of $77^{\circ}$ [5]. The purpose of the HIFiRE VII flight test program was to measure the thrust of the scramjet engine. The flight test was originally scheduled for June 2013, but after having been delayed, it has not been conducted yet. According to HIFiRE VII's mission profile, the flight test specified a $250 \mathrm{~kg}$ test vehicle and a VSB-30 booster. The test conditions were Mach 8.0 at an altitude of $34 \mathrm{~km}$ to $26 \mathrm{~km}$ and a coasting time of $4.6 \mathrm{~s}$ [6].

The first step of the verification process is to calculate the phased altitude and Mach number along the flight trajectory. The second step is to compare those results to the data from the references. The average error is $5.7 \%$ and the maximum error is $14.0 \%$. The errors are shown in Table 2-3. These errors

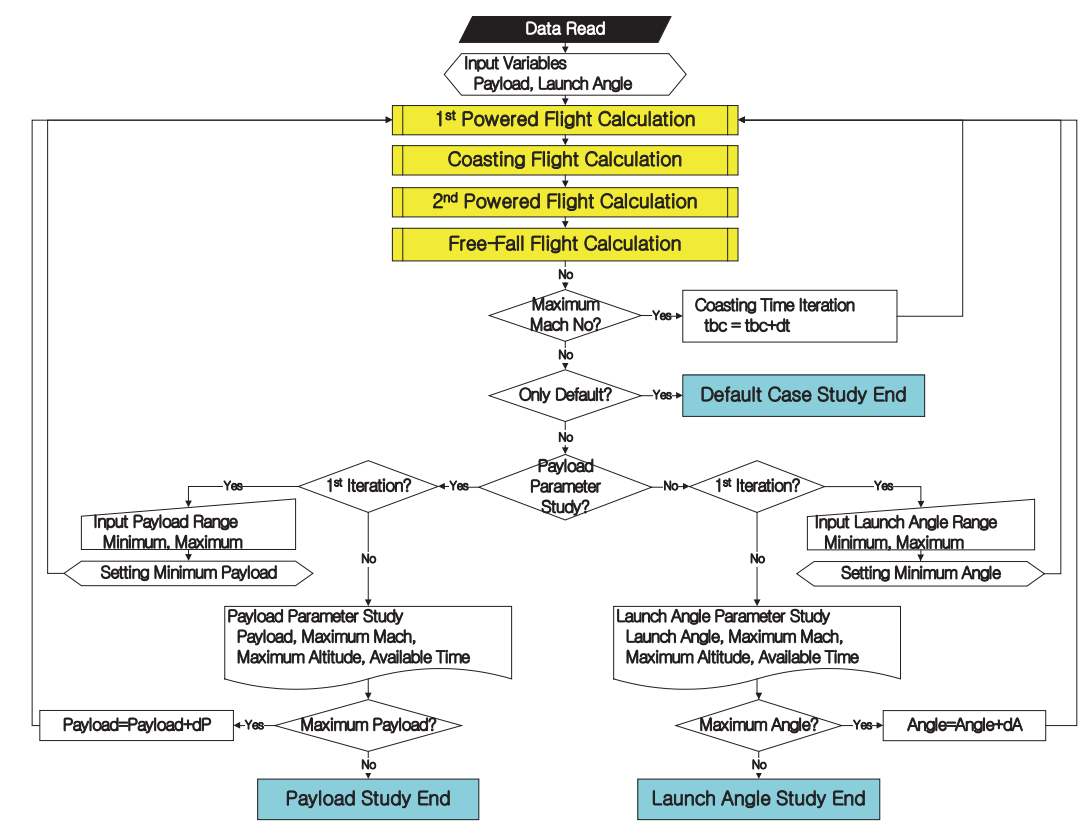

Fig. 4. Flow chart of flight performance analysis 
were caused by assumptions such as the stage separation point, thrust profile, and wing existence. Considering the aforementioned differences with real flight data, the results of the proposed analysis program are judged to be reliable enough to design the flight test.

\section{Preliminary Design of Flight Test}

\subsection{Sounding Rocket for Flight Test}

The specifications and performance of the domestic launch vehicles, shown in Table 4, were used to choose a sounding rocket that could conduct the flight test using a sub-scale RBCC engine. These specifications were compared to those of formally conducted overseas flight tests as shown in Table 1. Considering that the performance of the launch vehicles is based on total impulse, KSR-I has unacceptable performance because the total impulse of this vehicle is far lower than that of overseas sounding rockets in Table 1. KSRII and Hyunmoo-I (HM-I) are similar to the Terrier-Orion Improved used in HyShot and VSB-30 used in some of the HIFiRE flight tests, respectively.

Table 1. Sounding rockets in flight test programs [1]

\begin{tabular}{|c|c|c|c|c|c|}
\hline Program & Sounding rocket & $\begin{array}{c}\text { Weight (tonf) } \\
\text { without Payload }\end{array}$ & Thrust (tonf) & $t_{\text {burn }}(\mathrm{s})$ & $I_{\text {total }}(\mathrm{MNs})$ \\
\hline \multirow{2}{*}{$\begin{array}{c}\text { HyShot } \\
\text { FASTT } \\
\text { HIFiRE } 0,1\end{array}$} & \multirow{2}{*}{ Terrier-Orion Imp. } & \multirow{2}{*}{1.44} & 26.2 & 6.2 & \multirow{2}{*}{2.26} \\
\hline & & & 2.4 & 29.0 & \\
\hline \multirow{2}{*}{ HIFiRE 6} & \multirow{2}{*}{ Terrier-Oriole } & \multirow{2}{*}{2.04} & 26.2 & 6.2 & \multirow{2}{*}{4.22} \\
\hline & & & 9.4 & 28.5 & \\
\hline \multirow{3}{*}{ HIFiRE 2} & \multirow{3}{*}{ Terrier-Terrier-Oriole } & \multirow{3}{*}{3.08} & 26.2 & 6.2 & \multirow{3}{*}{5.82} \\
\hline & & & 26.2 & 6.2 & \\
\hline & & & 9.4 & 28.5 & \\
\hline \multirow{2}{*}{$\begin{array}{l}\text { ScramSpace } \\
\text { HIFiRE } 3,5\end{array}$} & \multirow{2}{*}{ S-30/Orion Imp. } & \multirow{2}{*}{1.60} & 9.7 & 28.9 & \multirow{2}{*}{3.42} \\
\hline & & & 2.4 & 29.0 & \\
\hline \multirow{2}{*}{ HIFiRE 4,7} & \multirow{2}{*}{ VSB-30 (S-31/S-30) } & \multirow{2}{*}{2.10} & 15.4 & 12.0 & \multirow{2}{*}{4.56} \\
\hline & & & 9.7 & 28.9 & \\
\hline \multirow{2}{*}{ HIFiRE 8} & \multirow{2}{*}{ VS-40 (S40TM/S44) } & \multirow{2}{*}{6.69} & 21.2 & 56.0 & \multirow{2}{*}{13.9} \\
\hline & & & 3.4 & 68.0 & \\
\hline
\end{tabular}

Table 2. Errors between HyShot II mission profile and analysis results [5]

\begin{tabular}{ccccccc}
\hline \multirow{2}{*}{ HyShot II } & \multicolumn{2}{c}{ AIAA 2006-2514 [4] } & \multicolumn{2}{c}{ Trajectory Program } & \multicolumn{2}{c}{ Error } \\
& Altitude $(\mathrm{km})$ & Mach no. & Altitude $(\mathrm{km})$ & Mach no. & Altitude & Mach no. \\
\hline $\begin{array}{c}\text { First stage } \\
\text { burn-out }\end{array}$ & 3.70 & 3.60 & 3.63 & 3.79 & $\mathbf{1 . 9 \%}$ & $\mathbf{5 . 3 \%}$ \\
\hline $\begin{array}{c}\text { Second stage } \\
\text { burn-out }\end{array}$ & 56.0 & 7.10 & 50.2 & 6.69 & $\mathbf{1 0 . 4 \%}$ & $\mathbf{5 . 8 \%}$ \\
\hline Apogee & 314 & - & 292 & & $\mathbf{7 . 0 \%}$ & - \\
\hline $\begin{array}{c}\text { Start } \\
\text { experiment }\end{array}$ & 35.0 & 7.60 & 35.0 & 7.40 & - & $\mathbf{2 . 6 \%}$ \\
\hline $\begin{array}{c}\text { Stop } \\
\text { experiment }\end{array}$ & 23.0 & 7.40 & 23.0 & 7.73 & - & $\mathbf{4 . 5 \%}$ \\
\hline
\end{tabular}

Table 3. Errors between HIFiRE VII mission profile and analysis results [6]

\begin{tabular}{ccccccc}
\hline \multirow{2}{*}{ HIFiRE VII } & \multicolumn{2}{c}{ AIAA 2009-7259 $[5]$} & \multicolumn{2}{c}{ Trajectory Program } & \multicolumn{2}{c}{ Error } \\
& Altitude $(\mathrm{km})$ & Mach no. & Altitude $(\mathrm{km})$ & Mach no. & Altitude & Mach no. \\
\hline $\begin{array}{c}\text { First stage } \\
\text { burn-out }\end{array}$ & 4.00 & 1.90 & 3.82 & 1.90 & $\mathbf{4 . 5 \%}$ & $\mathbf{0 . 0} \%$ \\
\hline $\begin{array}{c}\text { Second stage } \\
\text { burn-out }\end{array}$ & 41.0 & 7.30 & 41.3 & 8.32 & $\mathbf{0 . 1 \%}$ & $\mathbf{1 4 . 0 \%}$ \\
\hline Apogee & 320 & - & 342 & & $\mathbf{6 . 9 \%}$ & - \\
\hline $\begin{array}{c}\text { Start } \\
\text { experiment }\end{array}$ & 33.7 & 8.00 & 33.7 & 8.54 & - & $\mathbf{6 . 8 \%}$ \\
\hline $\begin{array}{c}\text { Stop } \\
\text { experiment }\end{array}$ & 25.8 & 8.00 & 25.8 & 8.71 & - & $\mathbf{8 . 9 \%}$ \\
\hline
\end{tabular}


The paper also calculated the Mach number and altitude for each of the launch vehicles with HyShot II's initial condition, in order to choose a proper sounding rocket for the flight test. The initial condition is a $110 \mathrm{~kg}$ payload and a $77^{\circ}$ launch angle. The results of each launch vehicle are shown in Figs. 5-6.

As shown in the figures, KSR-I is not a suitable booster for the flight test because the maximum Mach number for the launch vehicle only stays at sonic speed due to the

Table 4. Performance of domestic launch vehicles [7]

\begin{tabular}{|c|c|c|c|c|}
\hline- & $\begin{array}{l}\text { Weight (tonf) } \\
\text { without Payload }\end{array}$ & Thrust (tonf) & $t_{\text {burn }}(\mathrm{s})$ & $I_{\text {total }}(\mathrm{MNs})$ \\
\hline KSR-I & 1.25 & 8.8 & 18.4 & 1.59 \\
\hline \multirow{2}{*}{ KSR-II } & \multirow{2}{*}{1.61} & 24.0 & 3.9 & \multirow{2}{*}{2.78} \\
\hline & & 9.5 & 16.4 & \\
\hline \multirow{2}{*}{ HM-I } & \multirow{2}{*}{4.85} & 100.0 & 3.4 & \multirow{2}{*}{4.62} \\
\hline & & 4.5 & 29.0 & \\
\hline
\end{tabular}

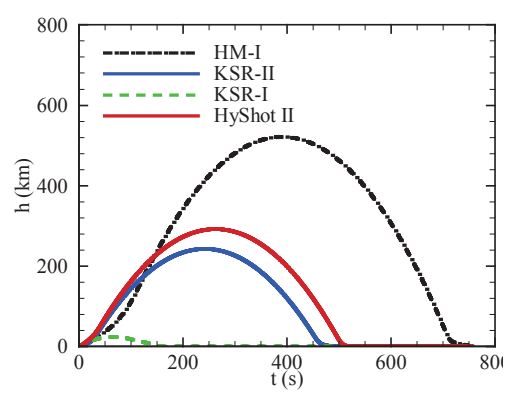

Fig. 5. Altitudes of launch vehicles

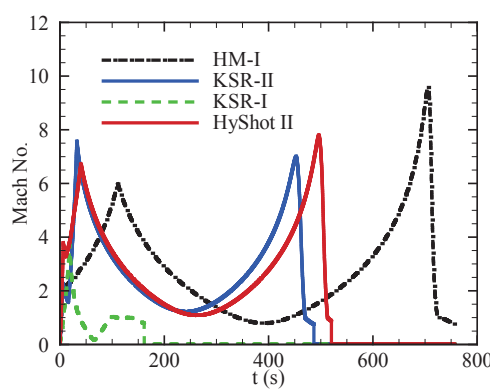

Fig. 6. Mach number of launch vehicles

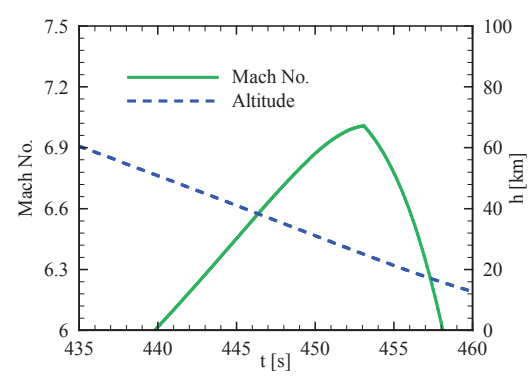

Fig. 7. RBCC test section using KSR-II wave drag force. However, KSR-II and HM-I show suitable performance because the maximum Mach number is similar to and greater than that of HyShot II. KSR-II is chosen as the sounding rocket for the flight test because HM-I is not stably secure and thus has limitations related to national defense.

The calculation results of KSR-II, shown in Table 5, were compared to the results of the HyShot II flight test in order to examine the performance of the chosen launch vehicle. The KSR-II flight test has a maximum of Mach 7.01 and an 18 s test time using the RBCC engine of the preceding study[2] operating at Mach 6.0 at an altitude of $25 \mathrm{~km}$, as shown in Fig. 7. If the test time is similar to that of HyShot II, it is expected that the KSR-II will execute the flight test at Mach 6.8 for $5.5 \mathrm{~s}$. The maximum acceleration and dynamic pressure of the flight test case using KSR-II are compared with those of HyShot II in order to examine the structural loading of the test vehicle. If KSR-II is used as the sounding rocket, the structural loading of the vehicle is less than the HyShot II flight test case using Terrier-Orion Improved. The maximum values of acceleration and dynamic pressure of the flight test case using KSR-II are 2/3 and 1/2 of the values in the HyShot II case on Table 4, respectively. Thus, the flight test results using KSR-II can be used to continue a preliminary design of the flight test for a sub-scale RBCC engine.

\subsection{Parametric Study}

To choose the optimal initial conditions for the flight test, parametric studies were conducted for the weight and launch angle of KSR-II. In this process, the maximum values of Mach number, altitude, acceleration, and dynamic pressure were arranged with variations of the initial conditions (payload and launch angle). The properties were calculated with Eqs. (10)-(12).

$$
\begin{aligned}
& \mathrm{a}=\frac{d v}{d t}=\frac{F}{m} \cos (\psi-\theta)-\frac{C_{D}}{m} \frac{\rho v^{2}}{2} \frac{\pi D^{2}}{4}-g \sin \theta \\
& h=\int v \sin \theta d t \\
& \mathrm{q}=\frac{1}{2} \rho v^{2}
\end{aligned}
$$

Table 5. Flight test capability of KSR-II

\begin{tabular}{c||cc}
\hline$M_{\text {test }} \geq 6.0$ & HyShot II & KSR-II \\
\hline$h_{\max }(\mathrm{km})$ & 292.3 & 242.9 \\
$M_{\max }$ & 7.80 & 7.01 \\
$q_{\max }(\mathrm{kPa})$ & $649.8 / 561.7$ & $285.0 / 342.0$ \\
$a_{\max }(\mathrm{g})$ & $26.4 /-19.4$ & $18.6 /-16.1$ \\
$h_{\text {test }}(\mathrm{km})$ & $66.0-11.3$ & $51.2-15.8$ \\
$t_{\text {test }}(\mathrm{s})$ & 25.5 & 18.3 \\
\hline \hline$t_{\text {test }}=5.5 \mathrm{~s}$ & HyShot II & KSR-II \\
\hline$h_{\text {test }}(\mathrm{km})$ & $35.0-23.0$ & $32.7-22.1$ \\
$M_{\text {test }}$ & 7.4 & 6.8 \\
\hline
\end{tabular}


At a fixed launch angle condition of $77^{\circ}$, a parametric payload study was conducted through the analysis program in the range of $50 \mathrm{~kg}$ to $300 \mathrm{~kg}$ in $10 \mathrm{~kg}$ increments. Figs. 8-9 show that the maximum values of Mach number, altitude, and acceleration are inversely proportional to the payload weight, and the maximum values of dynamic pressure increase after a $90 \mathrm{~kg}$ payload. The tendency of the maximum dynamic pressure is rapidly changed around $90 \mathrm{~kg}$, because the maximum values are on the descent section before 90 $\mathrm{kg}$ and are on the ascent section after $90 \mathrm{~kg}$. The maximum achievable Mach number during a flight test with a payload of $50 \mathrm{~kg}$ is Mach 7.4, and Mach 5.5 with a $300 \mathrm{~kg}$ payload. Thus, the heavier the RBCC engine, the lower the Mach number.

With a fixed payload of $110 \mathrm{~kg}$, a parametric study of the launch angle was conducted in increments of $2^{\circ}$ for a range of $60^{\circ}$ to $90^{\circ}$. Figs. 11-12 show that all of the results increase parabolically with increasing launch angle. Especially in terms of maximum acceleration, the rate of increase along

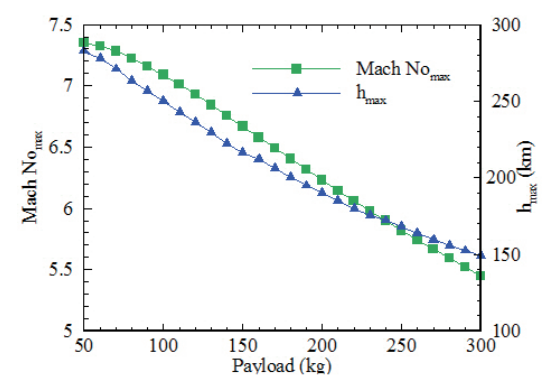

Fig. 8. Mach number and altitude for payload

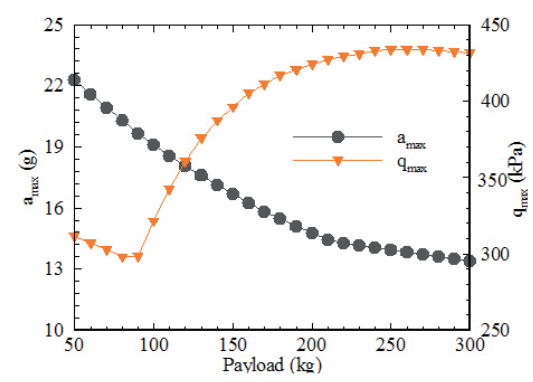

Fig. 9. Acceleration and dynamic pressure for payload

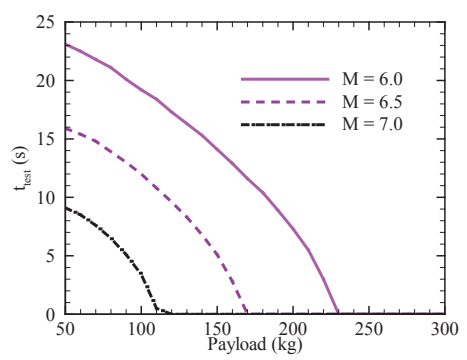

Fig. 10. Test time for payload the launch angle is smaller than that of the payload. The tendency of maximum dynamic pressure is different at around $70^{\circ}$, due to the same problem that occurs with the parametric case study of varying payloads. The maximum test Mach number that is capable of the flight test is 6.1 at a launch angle of $60^{\circ}$ and Mach 7.2 at $90^{\circ}$. The Mach number increases gradually with the launch angle.

The maximum values of acceleration and dynamic pressure affect the structural loading of the test vehicle including the RBCC engine. The rates of change of the maximum values along the payload are larger than that along the launch angle. Thus, the launch angle has a relatively small effect on the required strength of the onboard equipment.

The test time of the cases, shown in Figs. 10 and 13, have profiles similar to the maximum Mach number profiles. It is noted that the payload weight has more dominant effects about the maximum Mach number and the test time than the launch angle.

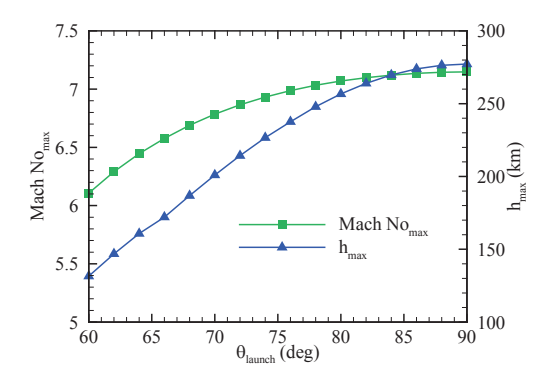

Fig. 11. Mach number and altitude for launch angle

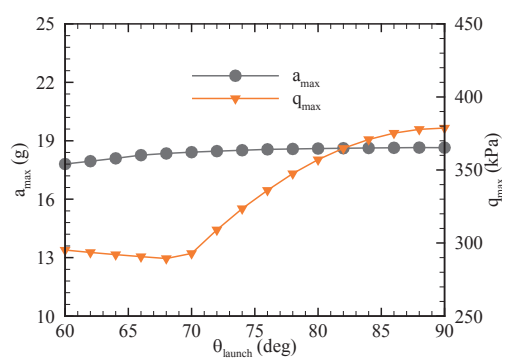

Fig. 12. Acceleration and dynamic pressure for launch angle

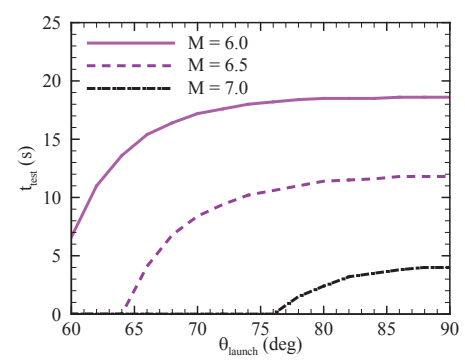

Fig. 13. Test time for launch angle 


\subsection{Flight Test using KSR-II}

A range of flight test properties is suggested for flight tests with a heavy or light test vehicle that includes an RBCC engine. It is important to set the launch angle of the sounding rocket to the optimal angle. Two considerations are shown below. First, the results of the parametric studies show that when the launch angle is close to $90^{\circ}$, the section of the test where the Mach number is over 6.0 is long and wide enough to conduct the flight test. Second, propulsion system tests of a hypersonic vehicle using a sounding rocket have generally been launched from a coastline to the ocean to avoid problems such as noise, toxic gases, and falling debris. Considering these two points, it is decided that an optimal launch angle for the flight test was to be $85^{\circ}$. The reasons are, the maximum Mach number of $85^{\circ}$ is similar to that of $90^{\circ}$ and the predicted crash point of the sounding rocket is the middle of an ocean.

The heavy payload, which is enough to be able to reach Mach 6.0, is derived as $230 \mathrm{~kg}$ in the $85^{\circ}$ condition, to design the flight test with a heavy test vehicle. In this case, the flight test shows a $3.2 \mathrm{~s}$ test time for Mach 6.0, a maximum of Mach 6.06, an acceleration of 14.2 times that of gravity, and a dynamic pressure of $461 \mathrm{kPa}$, as shown in Figs. 14-15, with an optimal coasting time of $8.3 \mathrm{~s}$.

The light payload is assumed to include a sub-scale RBCC engine, and was determined to be $50 \mathrm{~kg}$ through the overseas flight test cases at a launch angle of $85^{\circ}$, in order to design the flight test with a light test vehicle. In this case, the flight

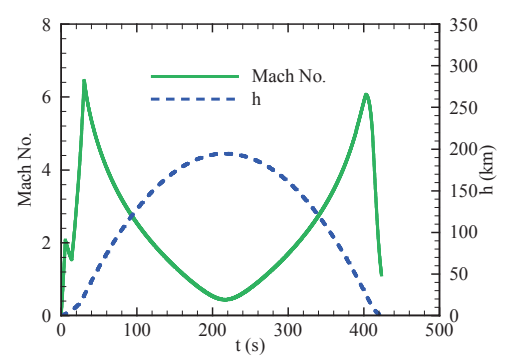

Fig. 14. Mach number and altitude of maximum payload, $230 \mathrm{~kg}, 85^{\circ}$

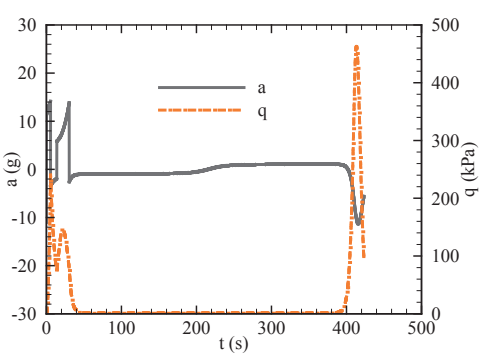

Fig. 15. Acceleration and dynamic pressure of maximum payload, 230 $\mathrm{kg}, 85^{\circ}$ test shows a 4.6 s test time for Mach 7.4, a maximum of Mach 7.51, an acceleration of 22.4 times gravity, and a dynamic pressure of $309 \mathrm{kPa}$, as shown in Figs. 16-17, with an optimal coasting time of $14.2 \mathrm{~s}$. If the test Mach number is reduced to 6.0 , the test time increases from $4.6 \mathrm{~s}$ to $23.2 \mathrm{~s}$.

Considering the results, it is expected that the maximum payload of the test vehicle to reach Mach 6.0 is $230 \mathrm{~kg}$, and the maximum test Mach number for the flight test is Mach 7.4 with a light payload of $50 \mathrm{~kg}$. Also, in the payload range of $50 \mathrm{~kg}$ to $230 \mathrm{~kg}$, the structural loading of the flight test using KSR-II is lower than that of the HyShot II case in terms of acceleration and dynamic pressure. Thus, the paper suggests that the flight test for a sub-scale RBCC engine using KSRII can be conducted and has as many advantages as the overseas flight test cases.

\section{Conclusion}

As a way toward the indigenous domestic RBCC program, the present paper introduces a preliminary design of a flight test conditions for a sub-scale RBCC engine using a sounding rocket, where a design of the sub-scale RBCC engine is going on in parallel for this flight test.

A flight performance analysis program for the sounding rocket was developed, and the analysis program was verified using references from other overseas hypersonic flight tests: HyShot II and HIFiRE VII. The average error of the analysis program is $5.7 \%$ and the maximum error of that is

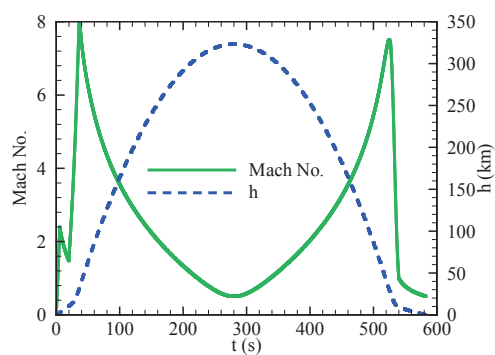

Fig. 16. Mach number and altitude of maximum Mach number, 50 kg, $85^{\circ}$

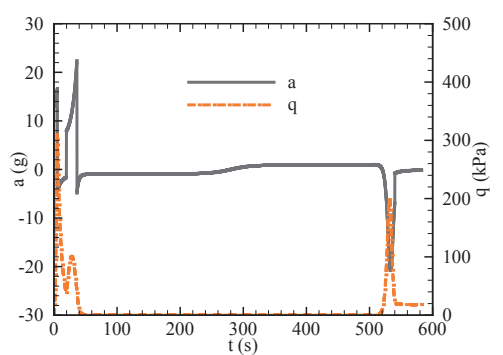

Fig. 17. Acceleration and dynamic pressure of maximum Mach number, $50 \mathrm{~kg}, 85^{\circ}$ 
$14.0 \%$, which shows that the results of the analysis program are reliable enough to be used to study a flight test for a hypersonic propulsion system. Several domestic candidate boosters were examined in same way for maximum altitude and Mach number that finally suggests that hypersonic flight tests can be performed successfully using a KSR-II.

The parametric studies were conducted to find the flight conditions with variations in payload and launch angle. The results showed that payload weight is directly proportional to the launch angle, while inversely proportional to the maximum Mach number of the test section. By calculating the flight test properties based on the formal results, it is found that the maximum payload able to reach Mach 6.0 is $230 \mathrm{~kg}$ in the heavy case and the maximum test Mach number with a $50 \mathrm{~kg}$ payload is Mach 7.4 in the light case. Present result is expected to facilitate the development of flight test programs for RBCC or hypersonic systems by suggesting design guidelines for hypersonic flight missions.

\section{Acknowledgement}

Present work was carried out with the support by the Space Core Technology Research Grants (NRF2013M1A3A3A02042430) of the National Research Foundation (NRF) of Korea, funded by the Ministry of Science, ICT and Future Planning (MSIP) of the Korean Government. It is also supported in part by the Advanced Research Center Program (NRF-2013R1A5A1073861) of NRF funded by MSIP contracted through Advanced Space
Propulsion Research Center at Seoul National University.

\section{References}

[1] Kim, H. S., Yang, W. S. and Choi, J. Y., "Sub-Orbital Hypersonic Flight Test Programs using Sounding Rockets and Small Launch Vehicles", Journal of The Korean Society for Aeronautical \& Space Sciences, Vol. 43, No. 3, 2015, pp. 243 256. DOI: 10.5139/JKSAS.2015.43.3.243

[2] Yang, W. S., Conceptual Design and Performance Analysis of RBCC for Flight Test using Sounding Rocket, Master's Thesis, Pusan National University, 2015.

[3] Sutton, G. P. and Biblarz, O., Rocket Propulsion Elements, Eighth Edition, John Wiley \& Sons, Inc., New Jersey, 2010.

[4] Fleeman, E. L., Tactical Missile Design, American Institute of Aeronautics and Astronautics, Virginia, 2001.

[5] Smart, M. K., Hass, N. E. and Paull, A., "Flight Data Analysis of the HyShot 2 Scramjet Flight Experiment," AIAA Journal, Vol. 44, No. 10, 2006, pp. 2366-2375. DOI: 10.2514/1.20661

[6] Smart, M. K. and Suraweera, M. V., "HIFiRE 7 Development of a 3-D Scramjet for Flight Testing," AIAA Paper 2009-7259, Proceedings of $16^{\text {th }}$ AIAA/DLR/DGLR International Space Planes and Hypersonic Systems and Technologies Conference, 2009, pp. 1-19.

[7] Moon, I. S., Moon, I. Y., Cho, S. B. and Ha, S. U., "Study on Methodology of Low Cost Sounding Rocket Development," Proceedings of the $41^{\text {th }}$ Korean Society of Propulsion Engineers Conference, 2013, pp. 45-51. 